\title{
ANALISIS STRATEGI BERSAING PADA INDUSTRI SONGKOK UD. ASWAD DAN SON DI DESA BUNGAH GRESIK
}

\author{
Sofiyanurriyanti ${ }^{1)}$, Febri Ariyanto ${ }^{2)}$ \\ Program Studi Teknik Industri, Universitas Teuku Umar ${ }^{1)}$, Universitas Qomaruddin ${ }^{2)}$ \\ Jl. Alue Peunyareng, Meulaboh, Kabupaten Aceh Barat 23615, PO BOX $59^{1)}$ \\ Jl. Raya Bungah no.1 Desa Bungah, Kabupaten Gresik ${ }^{2)}$ \\ email $^{1}$ : sofiyanurriyanti@utu.ac.id
}

\begin{abstract}
Abstrak
Pertumbuhan ekonomi pada usaha kecil dan menengah (UKM) sangatlah memilii peranan yang sangat penting dalam permbagunan ekonomi. Salah satunya yaitu di UD Aswad dan Son merupakan usaha kecil dan menengah kerajinan songkok yang berada di Wilayah Kecamatan Bungah Kabupaten Gresik. UD Aswad dan Son ini didirikan pada tahun 1986 oleh Bapak H. Tujuan penelitian ini adalah mendiskripsikan kondisi objektif di UD Aswad dan Son, menganalisis posisi keunggulan bersaing menggunakan analisis SWOT. Berdasarkan hasil analisis dan pembahasan maka dapat simpulkan faktor-faktor kekuatan (strengths) mempunyai nilai skor sebesar 2.49, faktor-faktor kelemahan (weaknesses) mempunyai nilai skor sebesar 0.50, peluang sebesar 2.64 dan ancaman sebesar 0.42 yang berarti UD Aswad dan Son mempunyai kekuatan yang lebih tinggi dibandingkan faktor kelemahan dalam menentukan strategi pemasaran dalam meningkatkan daya saing. Sedangkan dalam menentukan pilihan strategi pada diagram cartecius ditunjukkan ada kuandran IB yang merupakan stable growth dengan skor $\mathrm{S}<\mathrm{O}$ yaitu peluang pasar sangat berpengaruh pada UD. Aswan dan Son.
\end{abstract}

Kata kunci: Analisis Strategi Bersaing, Industri Kecil, IFE, EFE Matriks, SWOT Analysis.

\begin{abstract}
Economic growth in small and medium enterprises (SMEs) has a very important role in economic development. One of them is in UD Aswad and Son is a small and medium-sized handicraft business in the District of Bungah, Gresik Regency. UD Aswad and Son was founded in 1986 by Mr. H. The purpose of this study is to describe the objective conditions at UD Aswad and Son, analyze the position of competitive advantage using the SWOT analysis. Based on the analysis and discussion, it can be concluded that the strengths factors have a score of 2.49, weaknesses have a score of 0.50 , an opportunity of 2.64 and a threat of 0.42 which means UD Aswad and Son have strengths that are higher than the weakness factor in determining marketing strategies in increasing competitiveness. Whereas in determining the choice of strategy in the cartecius diagram it is shown that there is an IB quadrant which is a stable growth with a score of $S<O$, that is, market opportunity is very influential on UD. Aswan and Son.
\end{abstract}

Keywords: Competitive Strategy Analysis, Small Industry, IFE, EFE Matrix, SWOT Analysis.

\section{PENDAHULUAN}

Pertumbuhan ekonomi pada usaha kecil dan menengah (UKM) ini mempunyai peran yang sangat penting dalam pembangunan ekonomi nasional di Indonesia. UKM juga berperan besar dalam pendistribusian hasil hasil dari pembangunan motor penggerak dengan memiliki daya tahan yang sangat relatif kuat dalam menghadapi krisis ekonomi (Jafar, 2004).

Analisis strategi bersaing juga pernah dilakukan oleh Deo Leonardus (2017) pada UKM Batik Syafira dengan tujuan menganalisa strategi untuk meningkatkan daya saing pada UKM Batik Syafira. Hasil penelitiannya menunjukkan pada posisi UKM Batik Syafira terdapat pada kuadran I yang berarti bahwa kekuatan dan peluang (SO) lebih besar daripada kelemahan dan ancaman (WT).

Menurut Syuhardi, 2018 penelitian dengan judul Analisis Strategi Bersaing Industri Makanan Tradisional Khas Sumatera Barat hasil penelitiannyafaktor lingkungan eksternal yang menjadi peluang antara lain dukungan dinas koperasi dan UKM , dukungan instansi pemerintah 
Propinsi Sumatera Barat, peningkatan permintaan pada hari hari besar dan libur nasional, pasar pelanggan yang tinggi serta inovasi produk, kemasan dan mesin industry yang digunakan.

UD Aswad dan Son merupakan usaha kecil dan menengah kerajinan songkok yang berada di wilayah Kecamatan Bungah Kabupaten Gresik. UD Aswad dan Son ini didirikan pada tahun 1986 oleh Bapak H. Uddin. Usaha ini saat ini bagi para konsumen memang sebuah bisnis yang sangat cukup dilirik oleh para pelaku usaha. Menyadari hal tersebut usaha songkok sedang ramai dan jumlah kompetitor (pesaing) sangatlah ramai. Oleh karena itu pemilik usaha songkok ini juga memberikan ide ide kiat dalam usahanya dibidang yang sama yaitu songkok. Maka perlunya strategi bersaing yang inovatif dan kreatif yang perlu dilakukan pada usaha UD Aswad dan Son ini agar produk songkok yang ditawarkan dapat bersaing dipasar konsumen.

Usaha-usaha songkok ini juga banyak yang memproduksi produk yang relatif sama dalam skala usaha yang hampir sama. Usaha Songkok ini dulu bagian dalam songkok menggunakan kertas karton. Selain tidak tahan lama, songkok cenderung panas. Melihat kelemahan-kelemahan itu, UD Aswad dan Son ini beralih menggunakan bahan kain yang kaku dan keras sebagai pengganti kertas. Kain-kain itu diimpor dari Jepang, sedangkan bagian luar yang berbahan kain beludru lokal mapun impor dari Korea Selatan dan Amerika Serikat.

Kualitas premium menjadi ciri khas produksi UD Aswad dan Son. Sebab dulunya, pengrajin songkok rumahan memiliki daya tawar yang sangat rendah terhadap penentuan harga songkok dilingkungan pasaran. Sehingga dengan memproduksi kualitas terbaik, UD Aswad dan Son ini memisahkan diri dari persaingan industri songkok yang tak sehat. Terbukti, UD Aswad dan Son kini mampu bersaing dipasar domestik dengan sebaran pemasaran di Provinsi Jawa Tengah dan Jawa Timur.

UD Aswad dan Son memproduksi 5 jenis songkok yakni songkok biasa, Soga atau (songkok gaul atau songkok yang bermotif gambar), songkok bordir, songkok Aswad, dan songkok HMA. Kelima jenis songkok itu dibedakan berdasarkan kualitas bahan bakunya, terutama beludru. UD Aswad dan Son pun tak luput dari perhatian dari pembeli orang kecil. Menurut pemilik dari Suraji mengklaim bahawa pihaknya juga pionir dalam penjualan songkok untuk produk anak-anak. Anak-anak cenderung tidak suka memakai songkok karena gerah dan terlihat seperti orang tua. Maka UD Aswad dan Son membuat seri Soga atau Songkok Gaul atau Songkok Gambar untuk menarik minat anak-anak untuk memakai kopyah.
Menurut Pearce dan Robison (1997), usaha industry sangatlah membutuhkan strategi yang sesuai dengan kondisi industry untuk dapat bertahan di pasar dalam menghadapi persaingan, ancaman dan peluang pasar.

Hal inilah yang dapat mendorong penulis untuk menjadi usaha pada UD Aswad dan Son sebagai objek penelitian yang telah dilakukan. Adapun Tujuan penelitiannya ada mendiskripsikan kondisi objektif UD Aswad dan Son daerah Bungah Gresik, Menganalisis keunggulan bersaing dengan menggunakan analisis SWOT.

Menurut Porter (1980) strategi bersaing merupakan penetapan sasaran dan tujuan jangka panjang pada perusahaan yang diperlukan untuk mencapai sasaran dan tujuan tertentu. Analisis strategi bersaing ini menghubungkan antara perusahaan atau usaha yang berada dilingkungannya. Lingkungan yang sangat luas merupakan sebagai aspek utama dalam perusahaan antara lain aspek kekuatan sosial, aspek kekuatan ekonomi.

Aktivitas bisnis pada umumnya mempunyai tujuan untuk menghasilkan laba dengan kegiatan usaha bisnisnya jika tidak diduku g dengan strategi bersaing yang tepat. Dalam sebuah bisnis perusahaan juga harus memiliki strategi untuk terus menerus dalam mengambangkan produk usahanya lebih baik lagi dalam menciptakan produk baru dengan meningkatkan kualitas pelayanan terhadap kepuasan pelanggan (Jeff, 2001).

\section{TINJAUAN PUSTAKA \\ Strategi Bersaing}

Menurut Porter (1980), menjelaskan strategi bersaing adalah penetapan sasaran dan tujuan jangka panjang pada sebuah perusahaan dan arah tindakan yang sangat diperlukan untuk mencapai sasaran dan tujuan tertentu. Suatu perusahaan akan mempunyai keunggulan bersaing dalam kondisi yang menguntungkan dari lima faktor persaingan antara lain yaitu masuknya pendatang baru, kekuatan tawar menawar pemasok (supplier), serta persaingan diantara pesaing yang ada.

Sedangkan menurut Kotler, 2004 terdapt empat tingkat persaingan berdasarkan tingkat subtitusi produk antara lain, persaingan merek, persaingan industri, persaingan bentuk dan persaingan umum.

Semakin banyak persaingan dalam usaha yang sama atau sejenis dapat menyebabkan perusahaan akan merancang strategi dengan menggungguli persaingnya, yang sewaktu waktu menyerobot pasar yang sudah ada.

Menurut Kotler dan Amstrong, 2003 langkah langkah dalam menganalisis pesaing terdiri dari menganalisis pesaing perusahaan, memastikan 
tujuan pesaing, mengenali strategi pesaing, menilai kekuatan dan kelemahan persaing, memperkirakan reaksi pesaing dan memilih pesaing untuk diserang dan di hindari.

\section{Analisis SWOT}

Analisis SWOT menurut Kurtz, 2008 merupakan suatu alat perencanaan strategi yang sangat penting untuk membantu perencanaan pada kekuatan, kelemahan internal organisasi dengan kesempatan dan ancaman dari eksternal.

Menurut Rangkuti (2009), proses penyusunan strategi dalam analisis SWOT ada 3 tahapan antara lain:

\section{Tahap Pengumpulan Data}

Tahapan kegiatan dengan mengumpulkasn data suatu informasi yang terkait dengan faktor internal dan faktor eksternal dari perusahaan.

2. Tahap Analisa

Tahap analisa ini merupakan tahapan dengan menilai dari faktor internal dan faktor eksternal yang bedasarkan pada nilai bobot yang diberikan kepada masing-masing faktor terhadap keberhasilan perusahaan dalam industri dengan mengkalikan antara nilai bobot pada faktor dengan peringkat untuk menentukan rata-rata pada masing masing variabel.

3. Tahap Pengambilan Keputusan

Tahap ini dilakukan dengan mengakaji ulang dari empat strategi yang telah dirumuskan kedalam tahap analisa, berdasarkan pada matriks SWOT dan tahap akhirnya yaitu menyusun suatu rencana strategis yang telah disusun dalam melakukan kegiatan selanjutnya.

\section{METODOLOGI PENELITIAN}

Metode penelitian ini dilakukan di UD Aswad dan Son yang berada di wilayah Jawa Timur terletak di daerah Desa Bungah Kabupaten Gresik. Metode pengumpulan data ini dilakukan dengan menggunakan data primer dan data sekunder.

Teknik pengumpulan pada penelitian ini antara lain yang dilakukan dengan observasi secara langsung terhadap objek penelitian yang diamati kemudia mencatat informasi yang diperoleh, selanjutnya memberikan pertanyaan berupa kuisioner yang terstruktur dengan menggali informasi dilakukan kepada pemilik kerajinan songkok dan terhadap beberapa karyawan yang bekerja di UD Aswad dan Son

\section{ANALISIS DAN PEMBAHASAN DATA}

Hasil identifikasi faktor internal dan faktor eksteral dari hasil pembobotan yang telah dilakukan dengan melalui penyebaran kuisioner kepada pihak pemilik perusahaan dan karyawan perusahaan. Terdapat beberapa faktor identifikasi yaitu kekuatan, kelemahan peluang dan ancaman dalam matriks IFE dan matriks EFE. Setelah dilakukan pembobotan maka dapat diketahui weighted score, weigthed score terhadap posisi dari UD Aswad dan Son.

$$
\text { Bobot }=\frac{\text { Rating }}{\text { total rating }} \times 1
$$

Keterangan :

1 = dibawah rat-rata

$2=$ rata-rata

$3=$ diatas rata-rata

4 = sangat baik

\section{Analisis SWOT}

Analisis SWOT merupakan langkah langkah yang berdasarkan pada pengembangan dari matriks Internal Eksternal. Model analisa SWOT ini terdapat empat macam strategi utama yaitu SO, ST, WO dan WT. Analisis data yang diperoleh dari matriks EFE dan IFE. Formulasi strategi berdasarkan gabungan faktor internal dan faktor eksternal. Berikut ini merupakan Faktor Internal (IFAS), yang terdiri dari: a. Kekuatan (Strengths)

1) Basis pelanggan tersegmentasi dengan baik

2) Ada strategi yang kuat antara produk dan pelayanan

3) Pelanggan dapat melihat jaringan dengan mudah

4) Komunikasi pelanggan ditanggapi secara langsung oleh pemilik

5) Mendapat untung dari margin yang besar

6) Menjalankan aktivitas-aktivitas kunci dengan efisien

7) Memanfaatkan sumber daya disaat yang tepat

8) Menikmati hubungan kerja yang baik dengan mitra utama

9) Operasional efisien dalam biaya

b. Kelemahan (Weaknesses)

1) Basis pelanggan tidak tersegmentasi

2) Tidak ada sinergi antara produk dan layanan

3) Prospek gagal untuk memperhatikan jaringan

4) Jaringan komunikasi pelanggan tidak ditanggapi secara langsung oleh pemilik

5) Margin kami kecil

6) Pelaksanaan aktivitas kunci tidak efisien

7) Sulit memanfaatkan sumber daya disaat yang tepat

8) Hubungan kerja dengan mitra utama hanya menciptakan konflik

9) Operasional tidak efisien dari sudut biaya

Sedangkan pada faktor strategi eksternal (EFAS) terdiri dari faktor peluang dan faktor ancaman :

a. Peluang ( Opportunities ) 
1) Dapat melayani segmen pelanggan baru

2) Kebutuhan tambahan pelanggan dapat penuhi

3) Menemukan saluran-saluran mitra baru

4) Mempererat hubungan dengan pelanggan

5) Memiliki peluang penjualan silang, secara internal atau eksternal dengan mitra

6) Meningkatkan aktivitas kunci untuk meningkatkan penjualan sesuai dengan keinginan pelanggan

7) Pembelajaran untuk pegawai baru

8) Mitra melengkapi proposisi nilai

9) Dapat mengurangi biaya

b. Ancaman (Threats)

1) Pesaing mengancam pangsa pasar

2) Pesaing menawarkan harga atau nilai yang lebih baik

3) Saluran terancam menjadi tidak relevan bagi pelanggan

4) Hubungan pelanggan yang terancam memburuk

5) Margin terancam oleh pesaing

6) Aktivitas kunci dapat terganggu dan aktivitas kita juga terancam

7) Sumber daya manusia terancam pindah ke pesaing

8) Mitra tidak dapat melengkapi proposisi nilai

9) Adanya biaya yang mengancam untuk tumbuh lebih cepat dari pada pendapatan yang didukungnya.

Tabel 1. Penentuan Nilai bobot IFAS UD Aswad dan Son

\begin{tabular}{|c|l|c|c|c|}
\hline No & $\begin{array}{c}\text { Faktor- } \\
\text { Faktor } \\
\text { Strategi } \\
\text { Internal }\end{array}$ & Bobot & Rating & Skor \\
\hline 2 & $\begin{array}{l}\text { Basis } \\
\text { Pelanggan } \\
\text { tersegmentasi } \\
\text { dengan baik }\end{array}$ & 0.09 & 4 & 0.36 \\
\hline 3 & $\begin{array}{l}\text { Ada strategi } \\
\text { yang kuat } \\
\text { antara produk } \\
\text { dan layanan }\end{array}$ & 0.07 & 3 & 0,21 \\
\hline & $\begin{array}{l}\text { Pelanggan } \\
\text { dapat melihat } \\
\text { salurandengan } \\
\text { mudah }\end{array}$ & 0.07 & 3 & 0,21 \\
\hline 4 & $\begin{array}{l}\text { Jaringan } \\
\text { komunikasi } \\
\text { pelanggan } \\
\text { ditanggapi } \\
\text { secara } \\
\text { langsung oleh } \\
\text { pemilik }\end{array}$ & 0.09 & 4 & 0.36 \\
\hline 5 & Mendapat & 0.07 & 3 & 0.21 \\
\hline
\end{tabular}

\begin{tabular}{|c|c|c|c|c|}
\hline & $\begin{array}{lr}\text { untung } & \text { dari } \\
\text { margin } & \text { yang } \\
\text { besar } & \\
\end{array}$ & & & \\
\hline 6 & $\begin{array}{l}\text { Menjalankan } \\
\text { aktivitas- } \\
\text { aktivitas kunci } \\
\text { dengan efisien }\end{array}$ & 0.09 & 4 & 0.36 \\
\hline 7 & \begin{tabular}{ll}
\multicolumn{2}{l}{ Memanfaatkan } \\
sumber & daya \\
disaat & yang \\
tepat & \\
\end{tabular} & 0.07 & 3 & 0.21 \\
\hline 8 & \begin{tabular}{lr}
\multicolumn{2}{l}{ Menikmati } \\
hubungan kerja \\
yang baik \\
dengan mitra \\
utama
\end{tabular} & 0.09 & 4 & 0.36 \\
\hline 9 & $\begin{array}{l}\text { Operasinal } \\
\text { efisien dalam } \\
\text { biaya }\end{array}$ & 0.07 & 3 & 0.21 \\
\hline & Sub Total & 0.70 & & 2.49 \\
\hline \multicolumn{5}{|c|}{ Kelemahan (Weaknesses) } \\
\hline 1 & $\begin{array}{l}\text { Basis } \\
\text { pelanggan } \\
\text { tidak } \\
\text { tersegmentasi }\end{array}$ & 0.07 & 3 & 0,21 \\
\hline 2 & $\begin{array}{l}\text { Tidak ada } \\
\text { sinergi antara } \\
\text { produk dan } \\
\text { layanan }\end{array}$ & 0.07 & 3 & 0,21 \\
\hline 3 & $\begin{array}{l}\text { Prospek gagal } \\
\text { untuk } \\
\text { memperhatikan } \\
\text { saluran }\end{array}$ & 0.09 & 4 & 0.36 \\
\hline 4 & $\begin{array}{l}\text { Jaringan } \\
\text { komunikasi } \\
\text { untuk } \\
\text { memperhatikan } \\
\text { saluran } \\
\end{array}$ & 0.07 & 3 & 0.21 \\
\hline 5 & Margin Kecil & 0.09 & 4 & 0.36 \\
\hline 6 & $\begin{array}{l}\text { Pelaksanaan } \\
\text { aktivitas kunci } \\
\text { tidak efisien }\end{array}$ & 0.07 & 3 & 0.21 \\
\hline 7 & $\begin{array}{l}\text { Sulit } \\
\text { memanfaatkan } \\
\text { sumber daya } \\
\text { disaat yang } \\
\text { tepat } \\
\end{array}$ & 0.09 & 4 & 0.36 \\
\hline 8 & $\begin{array}{l}\text { Hubungan } \\
\text { kerja dengan } \\
\text { mitra utama } \\
\text { hanya } \\
\text { menciptakan } \\
\text { konflik } \\
\end{array}$ & 0.07 & 3 & 0.21 \\
\hline 9 & $\begin{array}{l}\text { Operasional } \\
\text { efisien dalam } \\
\text { biaya }\end{array}$ & 0.07 & 3 & 0.21 \\
\hline
\end{tabular}




\begin{tabular}{|l|l|l|l|}
\hline Sub Total & 0.30 & & 0.50 \\
\hline Total & 1.00 & & 2.99 \\
\hline
\end{tabular}

Sedangkan untuk perhitungan faktor eksternal (EFAS) disusun dengan cara yang sama seperti dengan cara menyusun matriks faktor internal (IFAS). Dapat ditunjukkan pada Tabel 2 dibawah ini :

Tabel 2. Penentuan Nilai bobot EFAS UD Aswad dan Son

\begin{tabular}{|c|l|c|c|c|}
\hline No & $\begin{array}{c}\text { Faktor- } \\
\text { Faktor } \\
\text { Strategi } \\
\text { Eksternal }\end{array}$ & Bobot & Rating & Skor \\
\hline 1 & $\begin{array}{l}\text { Dapat } \\
\text { melayani } \\
\text { segmen } \\
\text { pelanggan baru }\end{array}$ & 0.09 & 4 & 0,36 \\
\hline 2 & $\begin{array}{l}\text { Kebutuhan } \\
\text { tambahan } \\
\text { pelanggan } \\
\text { dapat penuhi }\end{array}$ & 0.09 & 4 & 0,36 \\
\hline 3 & $\begin{array}{l}\text { Menemukan } \\
\text { saluran-saluran } \\
\text { mitra baru }\end{array}$ & 0.09 & 4 & 0,36 \\
\hline 4 & $\begin{array}{l}\text { Mempererat } \\
\text { hubungan } \\
\text { dengan } \\
\text { pelanggan }\end{array}$ & 0.09 & 4 & 0.36 \\
\hline 5 & $\begin{array}{l}\text { Memiliki } \\
\text { peluang } \\
\text { penjualan } \\
\text { silang, secara } \\
\text { internal atau } \\
\text { dengan mitra }\end{array}$ & 0.07 & 3 & 0.21 \\
\hline 7 & $\begin{array}{l}\text { Meningkatkan } \\
\text { aktivitas kunci } \\
\text { untuk } \\
\text { meningkatkan } \\
\text { penjualan } \\
\text { sesuai dengan } \\
\text { keinginan } \\
\text { pelanggan }\end{array}$ & $\begin{array}{l}\text { Pembelajaran } \\
\text { untuk pegawai } \\
\text { baru }\end{array}$ & 0.09 & $\begin{array}{l}\text { Ancaman (Treath) } \\
\text { melengkapi } \\
\text { proposisi nilai }\end{array}$ \\
$\begin{array}{l}\text { Dapat } \\
\text { biaya }\end{array}$ & 0.07 & 3 & 0.21 \\
\hline Sub Total & 0.07 & 0.21 \\
\hline
\end{tabular}

\begin{tabular}{|c|c|c|c|c|}
\hline 1 & $\begin{array}{l}\text { Basis } \\
\text { pelanggan } \\
\text { tidak } \\
\text { tersegmentasi }\end{array}$ & 0.07 & 3 & 0,21 \\
\hline 2 & $\begin{array}{l}\text { Tidak ada } \\
\text { sinergi antara } \\
\text { produk dan } \\
\text { layanan }\end{array}$ & 0.07 & 3 & 0,21 \\
\hline 3 & $\begin{array}{l}\text { Prospek gagal } \\
\text { untuk } \\
\text { memperhatikan } \\
\text { saluran }\end{array}$ & 0.09 & 4 & 0.36 \\
\hline 4 & $\begin{array}{l}\text { Jaringan } \\
\text { komunikasi } \\
\text { untuk } \\
\text { memperhatikan } \\
\text { saluran }\end{array}$ & 0.07 & 3 & 0.21 \\
\hline 5 & Margin Kecil & 0.09 & 4 & 0.36 \\
\hline 6 & $\begin{array}{l}\text { Pelaksanaan } \\
\text { aktivitas kunci } \\
\text { tidak efisien }\end{array}$ & 0.07 & 3 & 0.21 \\
\hline 7 & $\begin{array}{l}\text { Sulit } \\
\text { memanfaatkan } \\
\text { sumber daya } \\
\text { disaat yang } \\
\text { tepat } \\
\end{array}$ & 0.09 & 4 & 0.36 \\
\hline 8 & $\begin{array}{l}\text { Hubungan } \\
\text { kerja dengan } \\
\text { mitra utama } \\
\text { hanya } \\
\text { menciptakan } \\
\text { konflik }\end{array}$ & 0.07 & 3 & 0.21 \\
\hline 9 & \begin{tabular}{|l|}
\multicolumn{2}{|l|}{ Operasional } \\
efisien dalam \\
biaya
\end{tabular} & 0.07 & 3 & 0.21 \\
\hline \multicolumn{2}{|c|}{ Sub Total } & 0.27 & & 0.42 \\
\hline \multicolumn{2}{|c|}{ Total } & 1.00 & & 3.06 \\
\hline
\end{tabular}

Berdasarkan pada Tabel 2. diatas faktor-faktor kekuatan (strengths) mempunyai nilai skor sebesar 2.49 sedangkan faktor-faktor kelemahan (weaknesses) mempunyai nilai skor sebesar 0.50, sedangkan nilai skor pada peluang (opportunities) sebsesar 2.64 dan skor ancaman (threats) sebesar 0.42 . Untuk menetukan pilihan strategi yang lebih spesifik dari nilai yang didapat dimasukkan ke dalam diagram pilihan strategi. 


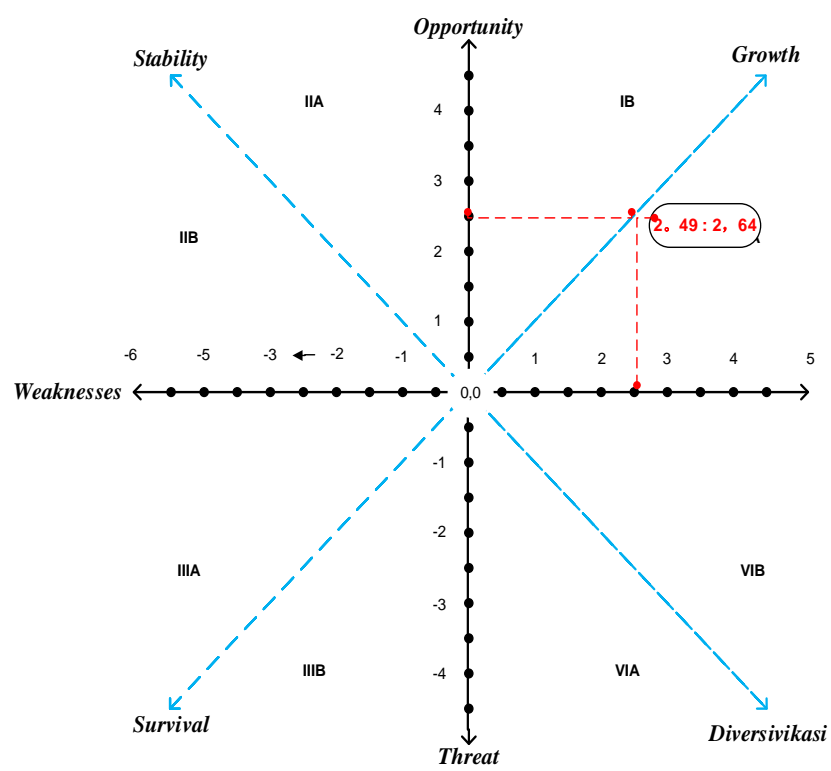

Gambar 1. Diagram Cartecius

Berdasarkan diagram dan tabel di atas yang didasarkan pada penghitungan SWOT UD Aswad dan Son dengan skor $S<O$, yakni peluang lebih besar dari pada kekuatan yang ada, dimana arah kebijakan Aswad dan Son dalam kondisi stable growth strategy.

\section{SIMPULAN}

Dari hasil penelitian ini dapat ditarik kesimpulan sebagai berikut :

a. Kondisi objektif UD Aswad dan Son Bungah Gresik mulai dari dari produksi, evaluasi produk/mutu, dan pemasaran produk yang diterapkan sudah cukup baik untuk bisa bersaing dengan kompetitor yang lain. UD Aswad dan Son Bungah Gresik juga perlu menggunakan strategi baru yang inovatif dan kreatif sesuaikan dengan keadaan pasar agar bisa mengungguli kompetitor lainnya.

b. Posisi keunggulan bersaing di UD Aswad dan Son Bungah Gresik, dengan menggunakan analisis SWOT (Strengths, Opportunities, Weaknesses, Threats). Dari hasil perhitungan bobot dan rating dari faktor internal maupun eksternal menghasilkan rangkaian skor yaitu: Kekuatan (Strenghts) sebesar 2.49, Kelemahan (Weaknesses) sebesar 0.50, Peluang (Opportunities) sebesar 2.64, Ancaman (Threats) sebesar 0.42 yang berarti bahwa kekuatan UD Aswad dan Son relatif lebih unggul dibanding dengan kelemahannya, sedangkan lingkungan yang saat ini dihadapi lebih besar daripada ancamannya. UD Aswad dan Son. dapat menggunakan strategi pertumbuhan secara bertahap sesuai skala prioritas dan strategi tersebut didukung dengan adanya alternatif peluang untuk menarik simpati pelanggan lebih banyak lagi dengan memberi jaminan kualitas produk untuk lebih memuaskan para pelanggannya.

\section{DAFTAR PUSTAKA}

Deo Lenardus. 2017. Analisis Strategi Bersaing Pada UKM Batik Syafira di Surabaya. Diakses melalui http://karya ilmiah.narotama.ac.id pada tanggal 29 Agustus 2019.

Jafar, H. 2004. Upaya Pengembangan Usaha Kecil dan Menengah (UKM). Infokop Nomor 25 Tahun XX. Diakses pada tanggal 25 Agustus 2019.

Louis E. Kurtz, David L. (2008). Pengantar Bisnis Kontemporer. Buku 1.Salemba Empat, Jakarta.

Madura, Jeff. (2001). Pengantar Bisnis Buku 2. Jakarta: Salemba Empat.

Kotler dan Armstrong terjemahan Sihombing 2001. Prinsip-Prinsip Pemasaran. Jakarta: ERLANGGA.

Pearch Dan Robinson 1997. Diakses dari http://hipni.blogspot.co.id/2012/02/ pengertian definisi manajemen strategi. html, Diakses 27 November 2015.

Porter 1980. Strategi Bersaing. Diakses Dari https://aditnobaka.wordpress.com /2012/10/08/pengertian-konsumen/, Diakses November 2015.

Rangkuti (2006). Pengertian dan rancangan diagram analisis SWOT. Jakarta: Bumi Aksara.

Syuhardi, 2018. Analisis Strategi Bersaing Industri Makanan Tradisional Khas Sumatera Barat. Jurnal of Applied Business and Economics, Vol 4 No 4. 350-359. 